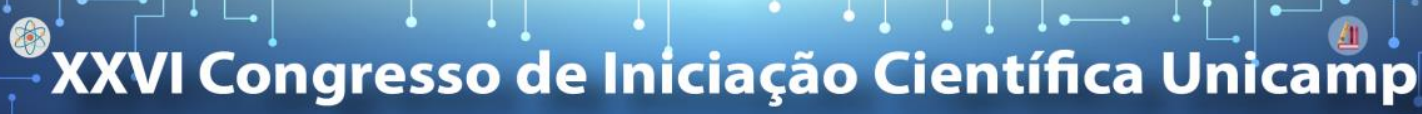

\section{ANÁLISE REOLÓGICA DE FORMULAÇÕES ESPESSANTES BIOPOLIMÉRICAS PARA PACIENTES COM DISFAGIA}

\author{
Sofia T. Garcia*, Jorge M. M. Vieira, Rosiane L. Cunha
}

\begin{abstract}
Resumo
A deglutição em pacientes disfágicos é feita de forma desordenada, podendo resultar na aspiração de alimentos líquidos. Esta condição pode ser aliviada pela utilização de espessantes que modificam as propriedades reológicas dos alimentos. Neste projeto, o desenvolvimento de novos espessantes contendo linhaça em sua composição se torna uma opção que além de garantir a viscosidade ideal para a aceitação do consumidor, considera aspectos como o teor nutritivo e funcional dos produtos em questão, pois grande parte das fórmulas comerciais é altamente calórica, traz poucos benefícios além do efeito espessante e possui recomendação de utilização genérica para o paciente.
\end{abstract}

Palavras-chave: Biopolímeros, reologia, disfagia.

\section{Introdução}

A disfagia consiste na dificuldade de deglutição de alimentos líquidos, sendo uma condição característica do envelhecimento e de doenças cerebrovasculares e neurodegenerativas, como Parkinson, Alzheimer, esclerose múltipla e AVC [1].

Estudos sobre espessantes se fazem necessários pois estes são capazes de proporcionar a ingestão de alimentos líquidos de maneira segura para pacientes disfágicos, evitando o rápido fluxo do bolo alimentar da boca para o esôfago, evitando aspiração pulmonar [2]. Devido à falta de padrões precisos para alimentos líquidos modificados direcionados para os pacientes disfágicos, atualmente eles são descritos de acordo com as recomendações provenientes das diretrizes da National Dysphagia Diet (NDD). Neste guia são encontradas recomendações para a categorização da viscosidade (a uma taxa de cisalhamento de $50 \mathrm{~s}^{-1}$ ), a qual é classificada em três níveis de consistência adequados: Nectar (51-350 cP), mel (351-1750 cP) e pudim (> $1750 \mathrm{cP})$.

O objetivo deste trabalho foi produzir formulações espessantes diferentes das comumente encontradas no mercado, utilizando a goma de linhaça como espessante e ingrediente funcional, de forma a atender necessidades de pacientes disfágicos e que possam ser aplicadas em várias matrizes alimentares.

\section{Resultados e Discussão}

A goma de linhaça foi extraída à temperatura ambiente e caracterizada segundo parâmetros de potencial zeta, teor proteico e viscosidade intrínseca. Diferentes formulações espessantes contendo gomas de linhaça, xantana, guar, amido e pectina foram preparadas de acordo a um delineamento experimental Plackett-Burman (Tabela 1). Dispersões aquosas contendo estas misturas e dos polissacarídeos isoladamente foram avaliadas quanto a propriedades reológicas. Varreduras de frequência $(0-10 \mathrm{~Hz})$ e curvas de escoamento $\left(0-400 \mathrm{~s}^{-1}\right)$ foram realizadas, e a partir desses dados verificou-se que a goma guar e pectina nas concentrações estudadas não apresentaram impacto estatisticamente significativo sob o parâmetro reológico.

Dessa forma, foi gerado um planejamento fatorial completo com os componentes que apresentaram efeito significativo anteriormente: amido modificado, goma xantana e goma de linhaça.
Tabela 1. Delineamento experimental Plackett-Burman.

\begin{tabular}{|c|c|c|c|c|c|c|c|c|c|c|c|}
\hline $\begin{array}{c}\text { Amido } \\
\text { modificado }\end{array}$ & Xantana & $\begin{array}{c}\text { Goma } \\
\text { Linhaça }\end{array}$ & $\begin{array}{l}\text { Goma } \\
\text { Guar }\end{array}$ & Pectina & $\begin{array}{l}\eta 10 \mathrm{~s}^{-1} \\
\text { (cP) }\end{array}$ & $\begin{array}{c}750 \mathrm{~s}^{-1} \\
\text { (cP) }\end{array}$ & $\begin{array}{l}\eta 400 \mathrm{~s}^{-1} \\
\text { (cP) }\end{array}$ & k & $\mathrm{n}$ & $\begin{array}{c}\mathrm{G}^{\prime} \\
(1 \mathrm{~Hz})\end{array}$ & $\begin{array}{c}\mathrm{G}^{\prime \prime} \\
(1 \mathrm{~Hz})\end{array}$ \\
\hline 3 & 0 & 3 & 0 & 0 & 3873 & 1407 & 380 & 16,49 & 0,37 & 12,12 & 18,01 \\
\hline 3 & 0,5 & 0 & 0,5 & 0 & 6291 & 1499 & 234 & 48,98 & 0,11 & 146,50 & 35,76 \\
\hline 0 & 0,5 & 3 & 0 & 0,5 & 2437 & 988 & 307 & 8,87 & 0,44 & 17,61 & 14,08 \\
\hline 3 & 0 & 3 & 0,5 & 0 & 5079 & 2289 & 529 & 18,87 & 0,49 & 14,93 & 15,68 \\
\hline 3 & 0,5 & 0 & 0,5 & 0,5 & 4837 & 1307 & 241 & 31,43 & 0,19 & 140,70 & 41,32 \\
\hline 3 & 0,5 & 3 & 0 & 0,5 & 16010 & 4379 & 820 & 102,28 & 0,19 & 181,50 & 84,77 \\
\hline 0 & 0,5 & 3 & 0,5 & 0 & 4468 & 1570 & 407 & 19,94 & 0,35 & 52,17 & 30,73 \\
\hline 0 & 0 & 3 & 0,5 & 0,5 & 3181 & 1282 & 396 & 11,67 & 0,44 & 9,42 & 14,89 \\
\hline 0 & 0 & 0 & 0,5 & 0,5 & 539 & 211 & 63 & 2,06 & 0,42 & 4,92 & 4,95 \\
\hline 3 & 0 & 0 & 0 & 0,5 & 311 & 168 & 75 & 0,75 & 0,62 & 0,60 & 1,33 \\
\hline 0 & 0,5 & 0 & 0 & 0 & 460 & 175 & 30 & 1,82 & 0,32 & 6,28 & 3,89 \\
\hline 1,5 & 0,25 & 1,5 & 0,25 & 0,25 & 1968 & 748 & 214 & 7,85 & 0,40 & 18,62 & 12,57 \\
\hline
\end{tabular}

Esse estudo final foi aplicado não só em água, mas também em suco de soja de laranja e leite, de forma a observar a influência das diferentes matrizes nas propriedades reológicas das formulações.

Em relação à influência da matriz alimentar, as formulações aplicadas em leite se classificaram no início do processo de mastigação (taxa de deformação de 10s 1) majoritariamente como "pudim". Já para o suco, o resultado obtido nos mesmos parâmetros foi da classificação "mel". A uma taxa de $50 \mathrm{~s}^{-1}$, apenas duas de dezessete formulações apresentaram características não seguras para consumo por pacientes disfágicos em qualquer matriz incorporada. Para taxas de deformação de $400 \mathrm{~s}^{-1}$, a maior parte das formulações se classificou entre "mel" e "néctar", independente da matriz aplicada.

Conjuntamente, foram realizadas análises colorimétricas das amostras para verificar possíveis alterações de cor no produto.

\section{Conclusões}

Após a extração e caracterização da goma de linhaça, foi possível verificar que sua incorporação juntamente a outras gomas gerou um bom resultado reológico, apresentando a vantagem do apelo funcional. A cor das amostras espessadas em relação às matrizes estudadas, apesar de apresentarem diferenças significativas, com maior intensidade na água, não alteraram a cor característica das mesmas.

\section{Agradecimentos}

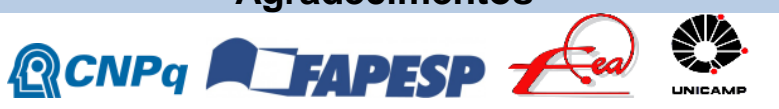

${ }^{1}$ Leonard, R.J., White, C., McKenzie, S., Belafsky, P.C., J. Ac. Nut. and Diet., 2014. 114, 2212-2672.

2 O'Leary, M., Hanson, B. and Smith, C., J. Food Sci. 2010. 75(6), 330-338. 